\title{
Principal Component Analysis for Fast Food Consumption among Teenagers of Sabour Block in Bhagalpur, India
}

\author{
Ruchi Kumari and Mamta Kumari*
}

PG Department of Home Science-Food and Nutrition, Tilka Manjhi Bhagalpur University, Bhagalpur-812 007, India

*Corresponding author:

\section{Keywords}

Fast food,

Teenagers, Indian fast food, Western fast food, Principal component analysis

\section{Article Info}

Accepted:

12 July 2019

Available Online:

10 August 2019

\section{A B S T R A C T}

This study assessed the consumption pattern of fast foods (Indian fast food, IFF; and Western fast food, WFF) and awareness of health hazards related to fast food among teenagers (boys and girls; 12-19 years). The data was collected for questionnaire related to fast food consumption viz., attraction for fast food, satisfaction with fast food, reason for cooking fast food at home, frequency of consuming fast food, Size of fast food preferred, reason for taking fast food with variables, favorite place for having fast food, choosing a particular place to consume, and having earlier any type of educational knowledge or educational programme about fast foods. PCA revealed that (1) attraction for fast food among teenagers is not for relaxation, but the advertisement lures teenagers to fast food, (2) preference for fast food influenced by its deliciousness and convenience, and when it comes to status symbol price doesn't matter; (3) cooking fast food at home is not due to a change from regular diet, (4) fast food consumption is not so frequent, it is twice a month mostly, (5) size of fast food, small and medium mostly preferred, (6) choosing the fast food influenced by the decrease in comfort/relax level in teenagers, (7) home cooked may not be satisfying to the teenagers, (8) choosing a particular place to consume fast food influenced by location of fast food corner to some extent, and (9) lack of regular curriculum based awareness led to shift for other awareness and educational programmes.

\section{Introduction}

Consumption of diet high in sugar, saturated fat, salt and calorie content in children can lead to early development of obesity, hypertension, dyslipidemia and impaired glucose tolerance. The concerns with fast food consumption in developing countries also include poor hygiene during preparation storage and handling leading to microbiological contamination. Fast foods have high level of fat and sugars that are not only unhealthy but addictive and that creates a vicious cycle making it hard for children to choose healthy food (Arya and Mishra, 2013). High content of trans-fat in commercially available fast foods predispose children to risk of future heart diseases (Asgary et al., 2009). Energy density of fast food is more than twice the recommended daily allowance 
for children (Printice and Jebb, 2003). Fast food intake leads to higher proportion of calories being derived from total and saturated fat. Moreover, the micronutrient content (carotene, vitamin A, vitamin C) of the fast food is also low. Low levels of calcium and magnesium is also found in the fast foods. Therefore experts attributed the current childhood obesity epidemic to fast foods (Ashakiran et al., 2012). In a study conducted in Hyderabad, children from high socio-economic status preferred fast foods to traditional foods despite their better nutritional knowledge (Vijayapushpam et al., 2003).

The consumption of fast foods is increasingly growing across the world, because of the changes and transitions in the lifestyle and dietary habits, age groups particularly adolescents and young adults, are inclined toward consuming fast food (Majabadi et al., 2016). Multinational food-chain like McDonald's has been the favorite in India for a very long time, it is followed by Indian food joint like Haldiram's. Other major favorites' food joints are being viz., Subway, Domino's and Pizza Hut. With increasing trend of fast food, awareness for the health hazards that come with eating fast food has become important. They believe "Nutrition is more important than the taste".

The present study was done to assess the consumption pattern of fast foods (Indian fast food, IFF; and Western fast food, WFF) and awareness of health hazards related to fast food among teenagers (boys and girls; 12-19 years). The data was collected for questionnaire related to fast food consumption viz., attraction for fast food, satisfaction with fast food, reason for cooking fast food at home, frequency of consuming fast food, Size of fast food preferred, reason for taking fast food with variables, favorite place for having fast food, choosing a particular place to consume, and having earlier any type of educational knowledge or educational programme about fast foods.. Principal component analysis (PCA) helped find out in what respect one sample is different from another, which variables contribute most to this difference, and whether those variables contribute in the same way (i.e. are correlated) or independently from each other. PCA extracted salient patterns related to fast food consumption among teenagers in the present study.

\section{Materials and Methods}

The present study was conducted at Sabour Block of Bhagalpur district in Bihar (India). A convenient selection of ten schools/colleges was made for study purpose. Total 500 respondents, which include 250 boys and 250 girls of age 12-19 years, were randomly selected from different schools and colleges residing in rural-urban areas. The permission to conduct study was obtained from the respective school principals. The questionnaire in English and Hindi was pretested to students before its usage in the study. It contained semi-structured questions on food frequency intake of fast foods, vegetables and fruits per week. The list of common food stuffs labeled as fast foods was also mentioned in the questionnaire so as make this concept very clear to all participants. Other questions such as years of fast food consumption, source of information, reasons for consumption, awareness about its health hazards, amount spent in a week on fast foods and parental consumption of fast foods were also enquired. Grossly incompletely filled forms were excluded from analysis.

Firstly, a pilot survey was conducted, to check that the questions we have asked are providing us the relevant information regarding the main objectives of our survey or 
not; and secondly, to check the various factors like approximate time needed to fill up a schedule, for getting the feedback of the respondent if they find any question irrelevant or illogical to check what type of response we are getting while doing the survey i.e. the respondent should not find the question uninteresting. Also the pilot survey helped us in finding out the most effective $\mathrm{w}$ ay to ask questions so as to get the best possible response from the respondent. Moreover, the pilot survey helped in pre-testing the schedule and to get an idea about the procedure of the survey. Ten schedules were given to respondents (teenagers) prior to actual survey.

Collected data from the field were properly analyzed with the help of several statistics tools as per the need of study. On the basis of collected data to draw different conclusions and inference, the analysis procedure were adopted as follows: (1) tabulation of data by using frequency tables and cross tabulation; (2) Chi-square $\left(\chi^{2}\right)$ test of independence; and Principal Component Analysis (PCA). Pvalue was calculated using online-calculator (https://www.socscistatistics.com/pvalues/chi distribution.aspx; https://www.graphpad.com/ quickcalcs/pvalue1.cfm). If the p-value was found to be less than 0.05 , it was considered that the variables are not independent of each other and that there is a statistical relationship between the categorical variables, and viceversa.

PCA enables you to detect sample patterns, like any particular grouping. PCA reduces the dimensionality of a dataset with a large number of interrelated variables while retaining as much of the variation in the dataset as possible. One free trial version of PCA software, available online (https://analyse-it.com/landing/principalcomponent-analysis-software) was used in the present study. A Scree plot was also constructed that visualizes the dimensionality of the data and reveals the cumulative variance explained by each principal component that help making decision on the number of components to keep to adequately describing a dataset using ad-hoc rules such as components with a variance $>0.7$ or where the cumulative proportion of variation is > $80 \%$ or $>90 \%$ (Jolliffe, 2002).

\section{Results and Discussion}

Popularity of fast food stuffs in the present age of urbanization is largely being attributed to quick preparation and convenience of finishing a meal within no time. Great taste, attractive appearance along with advertising has played a major role in attracting people particularly adolescents to the selling joints (Allamani, 2007; Dixon et al., 2007; Fister, 2005). Likely health threats of fast food (risk of heart disorders, infertility, poisoning increased level of cholesterol, obesity); poor quality of fast foods (use of expired ingredients, poor cooking methods, re-use of leftover oils); illness and poisoning (Majabadi et al., 2016; www.nhp.gov.in). Unfortunately, the current world's adaptation to a system of consumption of fast foods has resulted in several adverse effects on health. The energy density of fast foods had been found to be more than twice the recommended daily allowance for children (Printice and Jebb, 2003). The increased childhood obesity has led to increase in life-threatening conditions particularly non communicable diseases in developing countries (Ashakiran et al., 2012, Jaisheeba et al., 2012). Dental cavities another common ailment in school children can result due to dense sugar content in fast foods (Nisar et al., 2009).

Though, in our study the underweight category scored higher than the normal and overweight. Both underweight and overweight are not good for health. Health risks are associated with both. Being 
underweight can represent as many health concerns to an individual as being overweight can. If a person is underweight, their body may not be getting the nutrients it needs to build healthy bones, skin, and hair (article by Nall, 2018). Risks of being underweight includes osteoporosis; skin, hair, or teeth problems, getting sick frequently; feeling tired all the time; anemia; irregular periods; slow or impaired growth. Being underweight and not getting enough calories could mean a person may not develop as expected. Till date, relatively little information is available about health risks of people with low BMI. On the other side, being overweight or obese, puts us at a greater risk for heart disease besides high blood pressure (hypertension), high LDL cholesterol ("bad" cholesterol), low HDL cholesterol ("good" cholesterol), high triglycerides, high blood glucose (sugar), family history of premature heart disease, physical inactivity, and cigarette smoking among the others according to National Heart, Lung and Blood Institute (USA). Earlier reports support these findings that Fast foods popularity among children is due to taste, appearance and advertisements (Joseph et al., 2015). The results and discussion of the present study are detailed under following sub-headings.

\section{PCA for the attraction for fast food}

PCA for the attraction for fast food among teenagers with variable like it is due to advertisement, promotional offers, convenience, relaxation, changing life style/global culture, reputation among friends, and any other. According to the table, the first two principal components account for nearly $90.7 \%$ of the variance in the original six variables, whilst the first three components account for nearly $100 \%$ (Fig. 1A; Table 1). The first principal component is not strongly correlated with seven of the original variables. The first principal component doesn't vary with any variable. This component may not be viewed as a measure of attraction for fast food. The second principal component is correlated positively with variable, relaxation, and negatively with variable, aadvertisement. The third principal component increases with increasing variable advertisement and decreases with changing life style/global culture. The fourth principal component increases with increasing value of variable, relaxation as it is negatively correlated. This suggests that attraction for fast food among teenagers is not for relaxation, but the advertisement lures teenagers to fast food. Earlier reports of the Union of European beverages association (UNESDA) has laid down guidelines to restrict marketing communication to be placed in printed media, web sites, or programs aimed at children. It directs not to directly appeal to children to persuade parents to buy their products, nor should the promotional activities encourage children to consume larger quantities for participation (www.unesda.org/our-unesdacommitments-act-responsibly; Kaushik et al., 2011). In our country, media advertisement and publicity is under the control of ministry of information and broadcasting (Government of India) that can formulate strict guidelines related to quality of food products advertised in Indian media.

\section{PCA for reason for satisfaction with fast food}

PCA for Reason for satisfaction with fast food, namely, it is delicious, taste of food is Indianized, ethical issue, as a status symbol (show off of modernity), convenient and easily available, comparatively cheaper, and other reason was performed (Fig. 1B; Table 1). According to the Scree plot and Table, the first two principal components account for nearly $96 \%$ of the variance in the original six variables, whilst the first three components account for nearly $100 \%$. The first principal 
component is correlated with six of the original variables though not strongly. The first principal component increases with increasing Status Symbol (Show off of modernity), comparatively cheaper, and other while by decreasing with the value of Taste of food is Indianized, Ethical issue, Convenient and easily available. This suggests that these six criteria vary together. If three which are positively correlated increases, then the remaining three (negatively correlated) tend to decrease. The second principal component is correlated with four of the original variables, of these two variables were negatively correlated (It is delicious, 0.714, and ethical issue) and two positively correlated (convenient and easily available and comparatively cheaper). The third principal component increases with increasing status symbol (Show off of modernity) and decreases with comparatively cheaper. This suggests that when it comes to status symbol price doesn't matter. The fourth principal component increases with increasing variable, It is delicious and Convenient and easily available and by decreasing the value of Ethical issue. This suggests that preference for fast food influenced by its deliciousness and convenient and easily availability are negatively correlated.

\section{PCA for reason for cooking fast food at home}

PCA for reason for cooking fast food at home with variable, namely delicious taste, change from regular diets, modernity, time saving, nutritional value, any other. According to the table, the first two principal components account for nearly $85 \%$ of the variance in the original six variables, whilst the first three components account for nearly $100 \%$ (Fig. $1 \mathrm{C}$; Table 1). The first principal component is negatively correlated with one of the original variables i.e. change from regular diet. The first principal component increases with decreasing change from regular diet. This suggests that these six criteria vary together. If three which are positively correlated increases, then the remaining three (negatively correlated) tend to decrease. The second principal component is correlated with two of the original variables; of these one variables were negatively correlated (delicious taste) and one positively correlated (modernity). Schmidt et al., (2005) concluded that dietary intake of fast food is a determinant of diet quality in adolescent girls; hence, efforts to reduce fast-food consumption may be useful in improving the diet and risk for future cardiovascular diseases. According to the one report related to fast-food consumption, it is common among some of the families because the parents of such families belong to the service class and they do not have enough time to spend on preparing and cooking traditional foods (Majabadi et al., 2016).

\section{PCA for frequency of consuming fast food}

PCA for frequency of consuming fast food, namely, once almost every day, once in a week, twice a week, thrice a week, once in a month, twice a month, and occasionally was performed (Fig. 2A; Table 2). According to the table, the first two principal components account for nearly $100 \%$ of the variance in the original seven variables. According to the table, the first two principal components account for nearly $85 \%$ of the variance in the original six variables, whilst the first three components account for nearly $100 \%$. Earlier reports also had similar observation that respondents mostly eat once a week followed by once a month and not very often. Very few people eat fast food every day. Respondents preferred eating fast food between the meals and for dinner more than lunch. Very few people prefer eating fast food for breakfast (Shokeen, 2017). 


\section{PCA for size of fast food preferred}

PCA for size of fast food preferred, namely, small, medium, full, double, and not specific was performed. According to the table, the first two principal components account for nearly $95.7 \%$ of the variance in the original six variables, whilst the first three components account for nearly $100 \%$ (Fig. 2B; Table 2)

The first principal component is not correlated with five of the original variables strongly related to preference for size of fast food. The first principal component does not change with any of these variables related to the size of fast food. The second principal component is correlated with two of the original variables i.e. full and not specific size of fast food. The third principal component decreases with increasing variable small and medium size of fast food.

\section{PCA for reason for taking fast food with variables}

PCA for Reason for taking fast food with variables viz., as alternative food, diverse variety, ease of availability, taste, for comfort/relax, just for fun, lack of cooking skill, any other. According to the table, the first two principal components account for nearly $89.4 \%$ of the variance in the original six variables, whilst the first three components account for nearly $100 \%$ (Fig. $2 \mathrm{C}$; Table 2). The first principal component is not correlated with any of eight of the original variables (As alternative food, diverse variety, Ease of availability, Taste, for comfort/relax, just for fun, lack of cooking skill, any other reason) strongly of choosing the fast food. The first principal component doesn't vary with these variables. The second principal component is correlated with two of the original variables; these two variables were just for fun and lack of cooking skill. This component increases with increase in the value of these variables. The third principal component increases with increase in the value of any other reason and strongly positively correlated. The fourth principal component increases with decrease in the value of variable, for comfort/relax. This suggests that choosing the fast food influenced by the decrease in comfort/relax level in teenagers.

\section{PCA for favourite place for having fast food}

PCA was performed for favourite place for having fast food, namely, branded restaurant, local fast food outlet/corner/stall, school/college canteen, home delivery/parcel, home cooked, not specific, and all of them). According to the table, the first two principal components account for nearly $86.8 \%$ of the variance in the original six variables, whilst the first three components account for nearly $100 \%$ (Fig. 3A; Table 3). The first principal component increases with the decreasing value of variable Home cooked as favourite place for having fast food.

The second principal component is correlated with one of the original variables i.e. Fast food outlet/corner/stall. The third principal component increases with increasing the value of variable school/college canteen and by decreasing the value of variable, all of them as favorite place for having fast food (branded restaurant, fast food outlet/corner/stall, school/college canteen, home delivery/parcel, home cooked, not specific, all of them. Like first principal component, the fourth principal component also increases with decreasing the value of variable, Home cooked as favourite place for having fast food. This component can be viewed as a Home cooked may not be available or satisfying to the respondents. 


\section{PCA for choosing a particular place to consume}

PCA for choosing a particular place to consume fast food with variables viz., price, taste, convenience, quality, hygiene and safety, location, and nutritional value. According to the table, the first two principal components account for nearly $88 \%$ of the variance in the original six variables, whilst the first three components account for nearly $100 \%$ ((Fig. 3B; Table 3). The first principal component is not correlated with any of seven of the original variables strongly of reason for having fast food. The first principal component doesn't vary with change in the value of any of seven variables. The second principal component is correlated with one of the original variables, location of fast food corner. The third principal component increases with decrease in the value of variable, convenience. The fourth principal component is not correlated with any of seven of the original variables strongly of reason for having fast food.

PCA for choosing a particular place to consume fast food, namely, price, taste, convenience, quality, hygiene and safety, location, and nutritional value was performed. According to the table, the first two principal components account for nearly $88 \%$ of the variance in the original six variables, whilst the first three components account for nearly $100 \%$. The first principal component is not correlated with any of seven of the original variables strongly of reason for having fast food. The first principal component doesn't vary with change in the value of any of seven variables. The second principal component is correlated with one of the original variables, location of fast food corner. The third principal component increases with decrease in the value of variable, convenience. The fourth principal component is not correlated with any of seven of the original variables strongly of reason for having fast food.
PCA for having earlier any type of educational knowledge or educational programme about fast foods

PCA was performed to reduce the variables for "Respondents having earlier any type of educational knowledge or educational programme about fast foods" through involving variables, namely, regular curriculum, internet, magazine, newspaper, TV/radio, and health awareness programme. According to the table, the first two principal components account for nearly $83.3 \%$ of the variance in the original six variables, whilst the first three components account for nearly $100 \%$ (Fig. 3C; Table 3). The first principal component is correlated with three of the original variables (regular curriculum, internet, magazine, newspaper, TV/Radio, health awareness programme) regarding teenagers having earlier any type of educational knowledge or educational programme about fast foods. The first principal component increases with increase in the value of variables like magazine and TV/Radio and by decrease in the value of Regular Curriculum.

The second principal component is correlated with two of the original six variables, of this one variable was positively correlated with Newspaper and negatively correlated Health awareness programme. This component can be viewed as newspaper based awareness is good but there is need for improvement in health awareness programme. The third principal component increases with increase in the value of Health awareness programme and decrease in the value of variables, Internet. The fourth principal component increases with decrease in the value of variable, regular Curriculum. This component can be viewed as a why lack of regular curriculum based awareness led to shift for other awareness and educational programmes. 
Table.1 Correlation between principal component and variables related to Factor that attracts for fast food, Reason for satisfaction with fast food and Reason for cooking fast food at home

\begin{tabular}{|c|c|c|c|c|}
\hline \multicolumn{5}{|c|}{ Factor that attracts for fast food } \\
\hline \multirow[t]{2}{*}{ Variables } & \multicolumn{4}{|c|}{ Component } \\
\hline & 1 & 2 & 3 & 4 \\
\hline Advertisement & 0.177 & -0.540 & 0.634 & 0.080 \\
\hline $\begin{array}{l}\text { Promotional } \\
\text { offers }\end{array}$ & 0.406 & -0.375 & -0.084 & -0.469 \\
\hline Convenience & -0.447 & 0.263 & 0.047 & 0.090 \\
\hline Relaxation & 0.162 & 0.594 & 0.490 & -0.579 \\
\hline $\begin{array}{l}\text { Changing life } \\
\text { style/Global } \\
\text { culture }\end{array}$ & 0.429 & 0.128 & -0.527 & -0.193 \\
\hline $\begin{array}{l}\text { Reputation } \\
\text { among friends }\end{array}$ & 0.467 & 0.176 & -0.044 & 0.473 \\
\hline Any other & -0.419 & -0.314 & -0.262 & -0.411 \\
\hline \multicolumn{5}{|c|}{ Reason for satisfaction with fast food } \\
\hline It is delicious & -0.005 & -0.714 & -0.156 & 0.679 \\
\hline $\begin{array}{l}\text { Taste of food } \\
\text { is Indianized }\end{array}$ & -0.454 & 0.086 & -0.018 & 0.146 \\
\hline Ethical issue & -0.329 & -0.494 & -0.134 & -0.532 \\
\hline $\begin{array}{l}\text { Status Symbol } \\
\text { (Show off of } \\
\text { modernity) }\end{array}$ & 0.437 & -0.062 & 0.542 & 0.129 \\
\hline $\begin{array}{l}\text { Convenient } \\
\text { and easily } \\
\text { available }\end{array}$ & -0.363 & 0.436 & 0.066 & 0.458 \\
\hline $\begin{array}{l}\text { Comparatively } \\
\text { cheaper }\end{array}$ & 0.394 & 0.206 & -0.804 & 0.071 \\
\hline Other & 0.456 & -0.051 & 0.110 & -0.052 \\
\hline \multicolumn{5}{|c|}{ Reason for cooking fast food at home } \\
\hline Delicious taste & 0.285 & -0.619 & -0.305 & -0.493 \\
\hline $\begin{array}{l}\text { Change from } \\
\text { regular diet }\end{array}$ & -0.527 & -0.109 & 0.175 & -0.549 \\
\hline Modernity & 0.288 & 0.646 & 0.150 & -0.273 \\
\hline Time saving & 0.423 & -0.039 & 0.652 & -0.319 \\
\hline $\begin{array}{l}\text { Nutritional } \\
\text { value }\end{array}$ & -0.474 & 0.335 & -0.218 & -0.408 \\
\hline Any Other & 0.394 & 0.273 & -0.617 & -0.247 \\
\hline
\end{tabular}


Table.2 Correlation between principal components and variables related to Frequency of consuming fast food, Size of fast food preferred and Reason for taking fast food

\begin{tabular}{|c|c|c|c|c|}
\hline \multicolumn{5}{|c|}{ Frequency of consuming fast food } \\
\hline \multirow{2}{*}{ Variables } & \multicolumn{4}{|c|}{ Component } \\
\hline & 1 & 2 & 3 & 4 \\
\hline $\begin{array}{l}\text { Once almost } \\
\text { every day }\end{array}$ & 0.428 & -0.187 & -0.249 & \\
\hline Once a week & -0.434 & -0.144 & -0.742 & \\
\hline $\begin{array}{l}\text { Twice a } \\
\text { week }\end{array}$ & -0.074 & -0.717 & 0.307 & \\
\hline $\begin{array}{l}\text { Thrice a } \\
\text { week }\end{array}$ & 0.441 & -0.053 & 0.111 & \\
\hline $\begin{array}{l}\text { Once in a } \\
\text { month }\end{array}$ & -0.415 & -0.251 & 0.436 & \\
\hline $\begin{array}{l}\text { Twice a } \\
\text { month }\end{array}$ & -0.250 & 0.600 & 0.300 & \\
\hline Occasionally & 0.440 & 0.076 & 0.032 & \\
\hline \multicolumn{5}{|c|}{ Size of fast food preferred } \\
\hline Small & -0.476 & 0.284 & 0.549 & \\
\hline Medium & 0.469 & -0.327 & 0.741 & \\
\hline Full & 0.435 & 0.500 & -0.258 & \\
\hline Double & -0.458 & 0.393 & 0.154 & \\
\hline Not Specific & -0.393 & -0.639 & -0.243 & \\
\hline \multicolumn{5}{|c|}{ Reason for taking fast food } \\
\hline $\begin{array}{l}\text { As } \\
\text { alternative } \\
\text { food }\end{array}$ & -0.394 & 0.332 & 0.073 & -0.336 \\
\hline $\begin{array}{l}\text { Diverse } \\
\text { variety }\end{array}$ & -0.412 & -0.260 & 0.235 & -0.299 \\
\hline $\begin{array}{l}\text { Ease of } \\
\text { availability }\end{array}$ & -0.462 & -0.049 & 0.121 & -0.409 \\
\hline Taste & 0.384 & -0.335 & -0.204 & -0.319 \\
\hline $\begin{array}{l}\text { For } \\
\text { comfort/relax }\end{array}$ & 0.423 & -0.238 & 0.194 & -0.578 \\
\hline Just for fun & 0.278 & 0.501 & -0.031 & -0.390 \\
\hline $\begin{array}{l}\text { Lack of } \\
\text { cooking skill }\end{array}$ & 0.080 & 0.604 & -0.215 & -0.113 \\
\hline Any other & 0.228 & 0.186 & 0.893 & 0.174 \\
\hline
\end{tabular}

Note: correlation value above 0.5 are deemed important and boldfaced in the table 
Table.3 Correlation between principal components and variables related to Favorite place for fast food, particular place to consume fast food and earlier any type of educational knowledge or educational programme about fast foods

\begin{tabular}{|c|c|c|c|c|}
\hline \multicolumn{5}{|c|}{ Favorite place for fast food } \\
\hline \multirow[t]{2}{*}{ Variables } & \multicolumn{4}{|c|}{ Component } \\
\hline & 1 & 2 & 3 & 4 \\
\hline $\begin{array}{l}\text { Branded } \\
\text { restaurant }\end{array}$ & 0.461 & -0.262 & 0.306 & -0.425 \\
\hline $\begin{array}{l}\text { Fast food } \\
\text { outlet/corner/stall }\end{array}$ & 0.012 & 0.601 & -0.224 & 0.279 \\
\hline $\begin{array}{l}\text { School/college } \\
\text { canteen }\end{array}$ & 0.287 & 0.375 & 0.613 & -0.313 \\
\hline $\begin{array}{l}\text { Home } \\
\text { delivery/parcel }\end{array}$ & -0.387 & 0.428 & 0.037 & -0.098 \\
\hline Home cooked & -0.535 & -0.074 & -0.043 & -0.608 \\
\hline Not specific & -0.320 & -0.487 & 0.149 & -0.300 \\
\hline All of them & 0.408 & -0.057 & -0.675 & -0.418 \\
\hline \multicolumn{5}{|c|}{ Particular place to consume fast food depends on } \\
\hline Price & 0.412 & -0.357 & 0.103 & 0.434 \\
\hline Taste & -0.425 & 0.163 & 0.310 & -0.432 \\
\hline Convenience & 0.311 & -0.007 & -0.789 & -0.463 \\
\hline Quality & 0.381 & 0.435 & 0.249 & -0.301 \\
\hline $\begin{array}{l}\text { Hygiene And } \\
\text { Safety }\end{array}$ & -0.412 & -0.362 & -0.053 & -0.266 \\
\hline Location & 0.253 & -0.699 & 0.304 & -0.435 \\
\hline Nutritional Value & -0.418 & -0.193 & -0.338 & 0.246 \\
\hline \multicolumn{5}{|c|}{ Earlier any type of educational knowledge or educational programme about fast foods } \\
\hline $\begin{array}{l}\text { Regular } \\
\text { Curriculum }\end{array}$ & -0.526 & 0.180 & -0.010 & -0.647 \\
\hline Internet & -0.214 & -0.398 & $-\mathbf{0 . 7 7 0}$ & -0.229 \\
\hline Magzine & 0.533 & 0.117 & 0.067 & -0.489 \\
\hline Newspaper & -0.232 & 0.721 & 0.020 & -0.118 \\
\hline TV/Radio & 0.536 & -0.010 & -0.111 & -0.423 \\
\hline $\begin{array}{l}\text { Health awareness } \\
\text { programme }\end{array}$ & -0.228 & -0.525 & 0.624 & -0.312 \\
\hline
\end{tabular}


Fig.1 Scree plot depicting principal components for (A) Factor that attracts for fast food, (B) Reason for satisfaction with fast food, and (C) Reason for cooking fast food at home
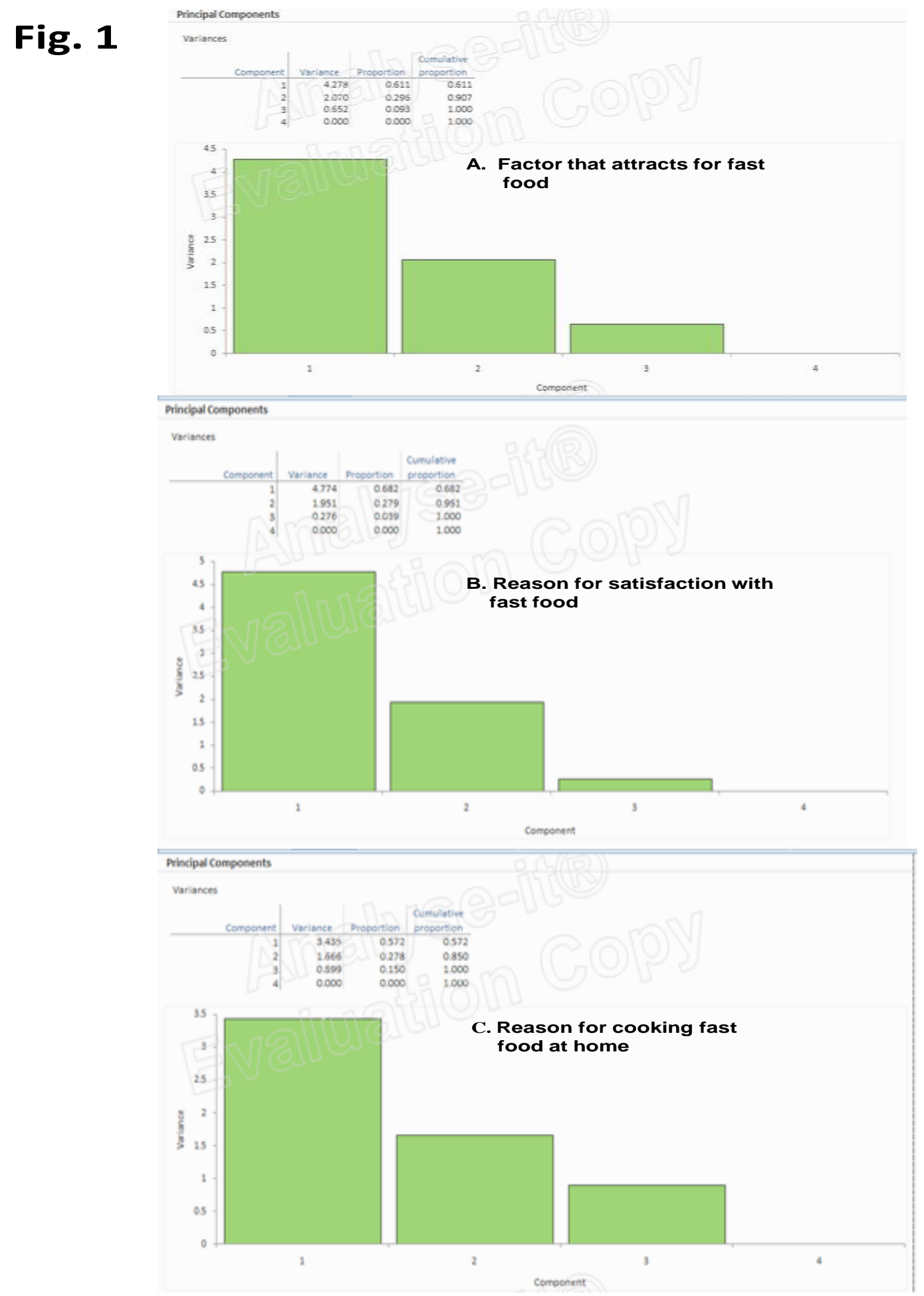
Fig.2 Scree plot depicting principal components for (A) Frequency of consuming fast food, (B) Size of fast food preferred, and (C) Reason for taking fast food

\section{Fig. 2}

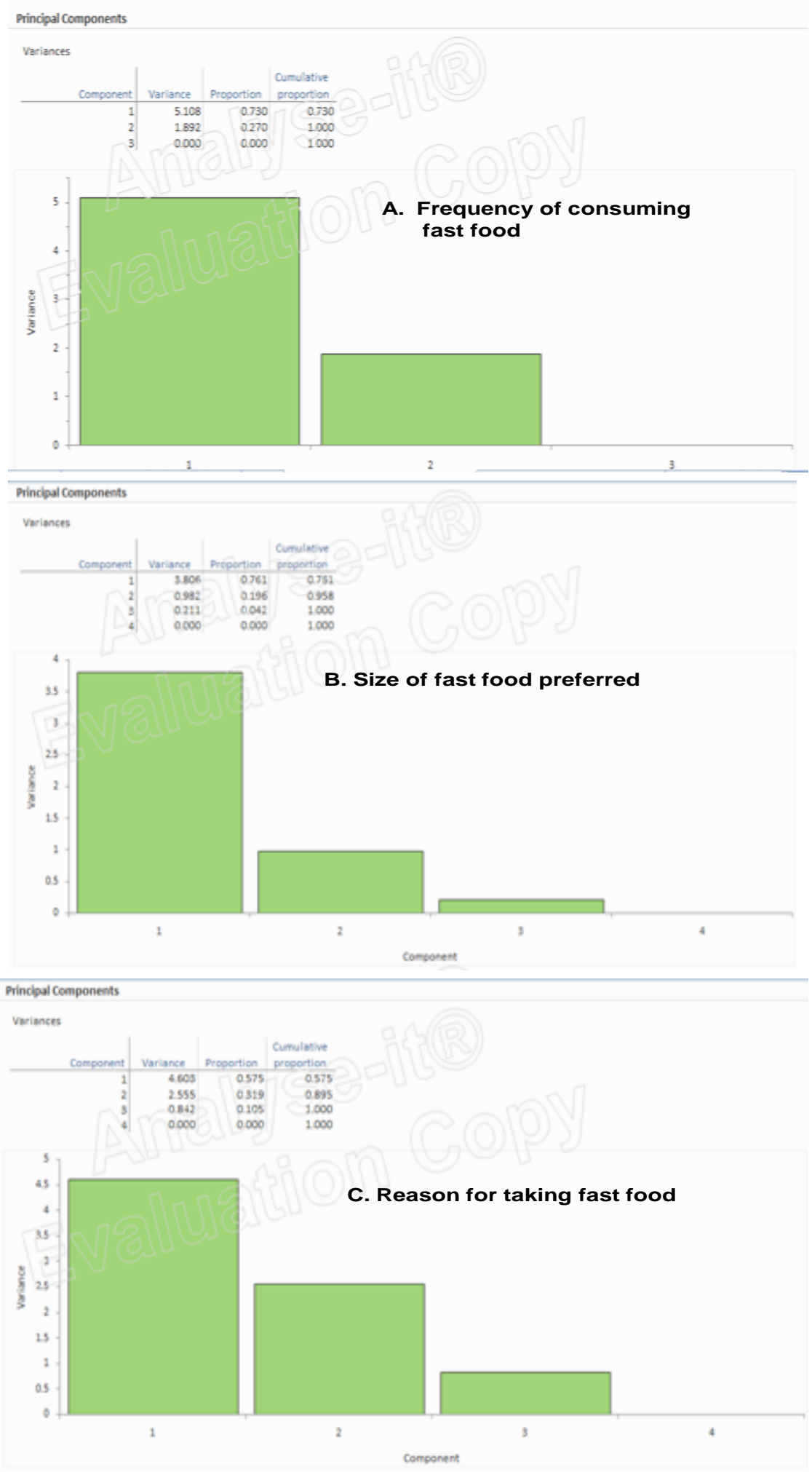


Fig.3 Scree plot depicting principal components for (A) Favorite place for fast food, (B) particular place to consume fast food, and (C) earlier any type of educational knowledge or educational programme about fast foods

Fig. 3
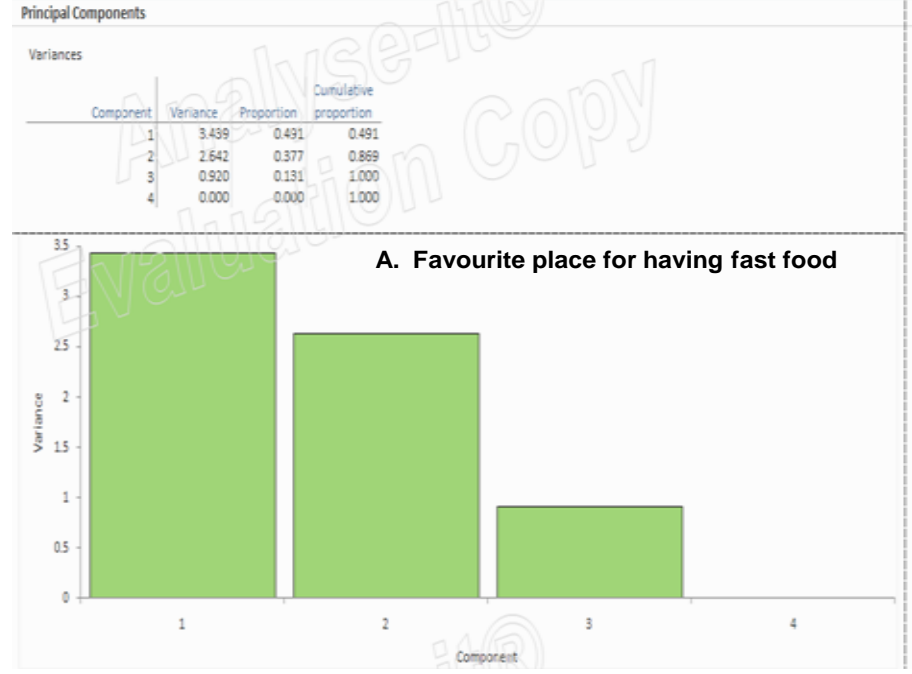

Whoipal Components

Varances
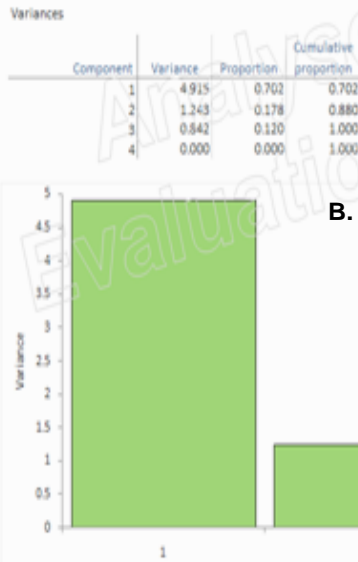

B. Choosing a particular place to consume fast food
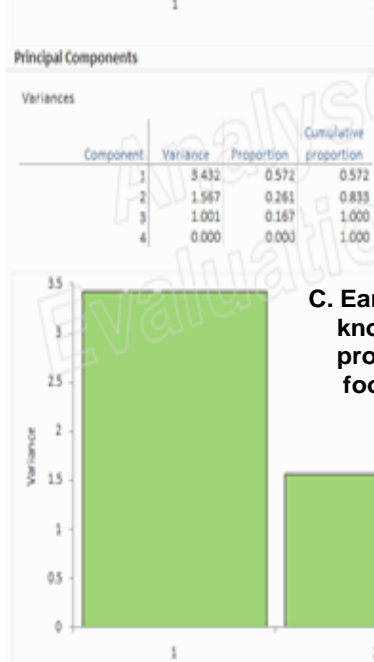

C. Earlier educational knowledge or educational programme about fast

foods

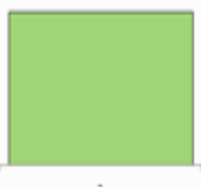


Prior survey reports showed that heavier TV use and more frequent commercial TV viewing were independently associated with more positive attitudes toward junk food and higher junk food consumption (Dixon et al., 2007). Furthermore, this survey also found that ads for nutritious foods promote selected positive attitudes and beliefs related to such foods. Earlier report suggested that the proximity of fast food joints to households could also predispose to increased consumption (Kaushik et al., 2011). Several studies emphasized on the importance of establishing a healthy eating behavior among children and adolescents, and interventions such as improving the convenience of healthy fast foods in school canteens and neighborhood stores, establishing policies to increase the cost of unhealthy fast food; need of stronger policies to provide healthier meals to students at schools by limiting access to low-nutrient, energy-dense foods and increasing the frequency, intensity, and duration of physical activity (Story et al., 2009; Kaushik et al., 2011).

In conclusion, PCA extracted salient patterns related to fast food consumption among teenagers in the present study. These were as follows, (1) attraction for fast food among teenagers is not for relaxation, but the advertisement lures teenagers to fast food, (2) preference for fast food influenced by its deliciousness and convenience, and when it comes to status symbol price doesn't matter; (3) cooking fast food at home is not due to a change from regular diet, (4) fast food consumption is not so frequent, it is twice a month mostly, (5) size of fast food, small and medium mostly preferred, (6) choosing the fast food influenced by the decrease in comfort/relax level in teenagers, (7) home cooked may not be satisfying to the teenagers, (8) choosing a particular place to consume fast food influenced by location of fast food corner to some extent, and (9) lack of regular curriculum based awareness led to shift for other awareness and educational programmes.

\section{Acknowledgement}

Authors thank the PG Department of Home Science-Food and Nutrition, Tilka Manjhi Bhagalpur University, Bhagalpur for their all support during the study.

\section{References}

Allamani A. Addiction, risk, and resources. Subst Use Misuse. 2007; 42:421-39.

Arya G., Mishra S. (2013). Effect of junk food \& beverages on Adolescent's health. IOSR Journal of nursing and health science, 1:26-32.

Asgary S, Nazari B, Sarrafzadegan N, Parkhideh S, Saberi S, Esmaillzadeh A, et al., (2009). Evaluation of fatty acid content of some Iranian fast foods with emphasis on trans fatty acids. Asia Pac J Clin Nutr. 18:187-92.

Ashakiran, Deepthi R. (2012). Fast foods and their impact on health. Journal of Krishna Institute of Medical Sciences University, 1:7-15.

Dixon HG, Scully ML, Wakefield MA, White VM, Crawford DA. The effects of television advertisements for junk food versus nutritious food on children's food attitudes and preferences. Soc Sci Med. 2007; 65: 1311-23.

Fister K. Junk food advertising contributes to young American's obesity. BMJ. 2005; 331: 1426

Jaisheeba AA, Sornaraj R, Gayathri K. Influence of westernized culture and changed dietary habits on the BMI status of the school children of Tirunelveli. International Journal of Pharm Tech Research. 2012; 4: 106577.

Jolliffe, I. (2002). Principal component 
analysis. Springer-Verlag, New York, Inc.

Joseph N, Nelliyanil M, Rai S, Y P RB, Kotian SM, Ghosh T, Singh M. Fast Food Consumption Pattern and Its Association with Overweight Among High School Boys in Mangalore City of Southern India. J Clin Diagn Res. 2015 9(5): LC13-7.

Kaushik J. S.r, Narang M., Parakh, A. (2011). Fast Food Consumption in Children. Indian Pediatrics 97 (48): 97-101

Majabadi H. A., Solhi, M., Montazeri, A., Shojaeizadeh D., Nejat S., Farahani F. K., Djazayeri A. (2016). Factors influencing fast-food consumption among adolescents in tehran: a qualitative study. Iran Red Crescent Med. J.,

Nall R. (2018) "What are the risks of being underweight?"; https://www.medical newstoday.com/articles/321612.php; retrieved from online on 11.04.2019

Nisar N, Qadri MH, Fatima K, Perveen SJ. Dietary habits and life style among the students of a Private Medical University, Karachi. Pak Med Assoc. 2009; 59: 98-101.
Printice AM, Jebb SA. Fast foods, energy density and obesity: a possible mechanistic link. Obesity Rev. 2003; 4: 187-94

Schmidt M, Affenito SG, Striegel-Moore R, Khoury PR, Barton B, Crawford P, et al., Fast-food intake and diet quality in black and white girls: the National Heart, Lung, and Blood Institute Growth and Health Study. Arch Pediatr Adolesc Med. 2005; 159(7): 626-31

Shokeen, S. (2017). A Study on Fast Food Consumption Pattern in India. Intern. J. Res. Engineer., [S.1.], 3(12): 10-15.

Story M, Nanney MS, Schwartz MB. Schools and obesity prevention: creating school environments and policies to promote healthy eating and physical activity. Milbank Q. 2009 Mar;87(1):71-100.

Vijayapushpam T, Menon KK, Rao R D, Maria Antony G. A qualitative assessment of nutrition knowledge levels and dietary intake of school children in Hyderabad. Public Health Nutr. 2003; 6:683-8.

\section{How to cite this article:}

Ruchi Kumari and Mamta Kumari. 2019. Principal Component Analysis for Fast Food Consumption among Teenagers of Sabour Block in Bhagalpur. Int.J.Curr.Microbiol.App.Sci. 8(08): 1675-1689. doi: https://doi.org/10.20546/ijcmas.2019.808.198 